\title{
Study on Effectiveness of Technological Innovations on the Development of SMEs
}

\author{
Dunhai Wang ${ }^{1}$ \\ ${ }^{1}$ Xi'an International University, Xi'an, Shaanxi, 710077 \\ hunter2011@foxmail.com
}

Keywords: Technical Innovation; SME; Constraints

\begin{abstract}
SMEs play a significant role in the economic development process, the rise and fall of SMEs determines our economic prosperity and development, this paper introduces the importance of technological innovation and makes a number of observations and recommendations.
\end{abstract}

\section{Introduction}

Since the 1980s, the rapid increase of the number of SMEs, relevant information, to the end of 2002, China's SMEs accounted for $90 \%$ of the total registration of all registered enterprises, whose output value, sales revenue, profits and taxes accounted for the total industry $60 \%, 58 \%$ and $40 \%$. Meanwhile, the sustainable development of SMEs and provide the community with a large number of employment opportunities. However, since China has joined the WTO, the increasingly fierce competition between SMEs, the core of the competition mainly for competing technologies, more directly expressed as the degree of technological innovation. The degree of technological innovation is directly related to the success of the enterprise, and further said that enterprises technological innovation has become an important factor in determining the level of regional economic differences and the development of enterprises. However, mechanisms, cultural, technological development lag historical formation of such progress in technological innovation of SMEs is not rapid. Our SME Technology Innovation research started late, only in recent years into the normalization track.

Technical innovation is the application of innovation and knowledge and new technologies, new processes, new production methods and management mode, improve product quality, develop new products, new services, market and commercialize occupy behavior. Innovative SMEs revitalized, and is constantly developing and changing market competition in an invincible position, it has become a development direction. With a simple formula: innovation $=\mathrm{New}+$ market value.

Market is an innovative carrier, everything depends on market demand innovation to operate out of the market's innovation is blind, meaningless. Innovation is the real sense of innovation, rather than the formal innovations, such as television production, if only to change the packaging, advertising overwhelming publicity, rather than innovation to change its function, then certainly not the kind of TV long-term occupation of the market. If only the new view, the focus on innovation, new product features are many and complex, difficult to sell, or the new product input-output ratio underestimation, or the creation of 0 degree before new awareness is unclear, duplication or even identical with people, will result in innovative mistakes.

Innovation is not updated and unconventional. In China, the traditional production methods and thinking habits hinder the company's development and social progress, and unconventional behavior has often not been accepted, this much-needed change. Therefore, the concept of innovation is easy with updates and unconventional, innovation confused. Meanwhile unconventional behavior but also to cover the enterprise is closely related to the true meaning of innovation.

\section{The main types of SME Technology Innovation}

According to different standards, technological innovation of SMEs can be divided into different types, from the perspective of this article focuses on innovative ways be classified in the 
introduction of technological innovation of SMEs.

Product innovation is the production and operation of SMEs in the process of the product, its own production or business engaged in product improvement, increase innovation or invention. It can be divided into two types of important innovation and incremental innovation. Important product innovation refers to new product innovation, or a combination of existing technology to achieve new applications; incremental product innovation is the use of new materials, new accessories and other products to improve performance or reduce product costs, or by changing the product locally Improved product and the entire system. In general, an important influence on the development of innovative enterprises, affecting the incremental innovation of enterprises big and small, but the former are often more difficult to achieve, investment is also large; the latter is easier to achieve. Because of the limited level of technology and innovation capacity of SMEs, the technological innovation activities generally incremental innovation based. Service innovation is the result of the rise of the knowledge-intensive service sector, including both new ideas, new ideas into new or improved services, and including changes in the existing organizational structure introduce new services, such as various financial derivatives, etc., the current rise of network services also service innovation success stories. Since the service innovation investment is small and fast changes in market demand, and thus is one of the most suitable type of technological innovation characteristics of SMEs.

Research and technology innovation is the introduction of new and improved production methods which are significant to improve existing products or improve production efficiency. Most process innovation is incremental, investment size and difficulty are more suitable characteristics of SMEs, which is also an important way for SMEs technological innovation. Between product innovation, service innovation and process innovation often influence each other, interacting with each other and promote each other, and closely related to the direct business activities of SMEs, and thus have greater universality, occupies an important position in technological innovation activities in SMEs .

SME research and development activities can be divided into its own research and development and joint research and development of two types. Which is limited by its own research and development by many factors, for business requirements are relatively high, only a limited number of base (including human resources and financial support, etc.) good business, but it should improve its research and development capabilities of SMEs technology cooperative research and development including SMEs and universities, research and development institutions and large enterprises cooperation; innovation main direction. SMEs, cooperative research and development activities are more fit and universal. Statistics show that, in relying on the help of universities and research institutions, as well as using a variety of public resources, SMEs demonstrate greater efficiency and enthusiasm. In addition, the active participation of the government's research and development activities is also an increasingly popular form. For example, in recent years the core of the EU SME policy is guided more SMEs to participate in research and development into the framework of the EU program. With the development of future high-tech industry, small and medium enterprises will become increasingly involved in high-tech research and development activities.

Technology transfer refers to the formation of an organization or within areas of particular purpose technology, knowledge or information is applied to the process of adoption or other organization, in the field or to serve other purposes. Technology transfer on technological innovation activities of SMEs has a special significance, often for government and policy makers that attention. Technology transfer in a variety of technology transfer between the principals, including between different SMEs, between SMEs and large enterprises, between SMEs and universities, SMEs and non-profit research institutes, SMEs and government between research institutions, between SMEs and international research institutions, between SMEs and foreign enterprises, etc. as well as with a number of small and medium enterprises engaged in technology transfer intermediaries. Encourage technology transfer activities for SMEs, it is to achieve a lot of important research commercialization channels. 


\section{The Necessity of Technological Innovation}

Mainstay of technological innovation enterprises, innovative enterprises to advance awareness, research and studies market trends at the same time, organize technical strength, mobilize all favorable factors, increase research and development efforts, improve the technological content of their products, to produce a universal subject the market and new marketable products. Constantly cultivate new economic growth points and technological growth, and truly raise the level of economic cut to leading technology and industrial upgrading track.

Technological innovation can boost domestic demand. A variety of new products and the development of appropriate national conditions and regional markets, and further to meet market demand, enhance the overall strength of enterprises, must focus on cultivating new economic growth point, strive to foster innovative SMEs, its resources can be fully utilized, and it can reduce the pressure on the government job placement.

Technological innovation can enable SMEs to maintain vitality. With the progress and development of science and technology, the production and operation of enterprises are undergoing significant changes. Internet penetration of information technology, consumer demand makes it uneven transfer market demand will inevitably require companies to use high-tech means to carry out technological innovation, through innovation, allows businesses in product development, research, production and other aspects there is reasonable order of arrangement, so that enterprises full of vigor and vitality.

\section{SME Technology Innovation Constraints}

However, due to the influence of the size of SMEs, financial and many other factors, there are many constraints in terms of enterprise technology innovation. Specific features:

Firm size and capital. SMEs due to output, output value and profits, etc., we can not continue to innovate the product, after the successful development of a product into the market several years without easily changing their appearance. Until the product backlog caused by the loss, before considering the transition, but a heavy burden has led companies.

Enterprise technology innovation is not enough emphasis. Currently, the role of the majority of SMEs to technological innovation in improving the competitiveness of the understanding is not enough, the production of the product delay the passage of the traditional production methods, the curing of an original idea, the lack of research and the ability to control the market, making the business managers do not know the the importance of technological innovation to. In the process of production and sales of the product, heavy marketing, light technology; re-introduction, light innovation and digestion.

Unstable innovative talents. Innovative talent is the most active, the most critical factor is the fundamental enterprise technology innovation. SMEs by ideas, capital and external environment, often lack the technical developers the necessary attention, did not establish effective competition incentives and research environment, the researchers do not want to cause most people keep their jobs, and cause brain drain.

Market competition is not standardized. At present, China's market system is not perfect, and many factors of production market, especially the technology market is not really set up, unreasonable price system resulting in product prices do not truly reflect the technological content of products; unfair competition and rampant counterfeit and shoddy products, the pushed to the brink of bankruptcy companies.

\section{Strategies for SME Technology Innovation}

Enhance the concept of enterprise technology innovation. Enhance their technological capabilities, a long investment need of enterprises, cultivate, need a better environment for development, but more needs innovative ideas for sustainable development. First, companies must clear direction of innovation, must be guided by the market, the establishment of corporate 
consulting and planning agencies, the creation of enterprise well-known brands, innovation, rather than innovation will die. Qingdao Haier Group's development has proved that only enhanced the concept of technological innovation, development potential, the formation of the company's core technology in order to survive and develop.

Innovation Network means conducive to innovation in regional governance structure, with the other companies to form networks can promote innovation, or that innovation can occur when enterprises to solve the problem through the network. Innovation Network is a structure, a multi-agency created by people, such as associations and intermediary organizations, to enable enterprises to strengthen ties and the formation of a stable and cooperative innovation requires a high degree of trust between enterprises.

The establishment of enterprise technology innovation environment. In the market competition, technological innovation and market competition body shape adapted to continuously create favorable business technology innovation market structure; establish / entrepreneur market 0 as soon as possible, creating a number of good at organizing technical innovation entrepreneurs; to make the competition more efficient and more effective incentive for companies to technological innovation, we must continue to improve supporting measures to maintain the dynamic of competition.

\section{Conclusion}

Proposed theory is applied in order to be able to practice, combined with technical innovation theory above analysis of SMEs to foreign technological innovation of SMEs as a reference. The paper further proposes the promotion of SMEs from two different angles and government enterprises Conception of further development of technological innovation. For governments at all levels, the first to establish a favorable macro SME Technology Innovation management system; improve social service support system; by the necessary economic means to support, guide and regulate the technological innovation of SMEs. For SMEs, the past technological innovation theory that the SMEs in the most disadvantaged innovative power, so more emphasis on government in technological innovation as the neglect of SMEs themselves may play a role in which. In fact business is the real subject of innovation, the government only play a supporting role, in order to enable SMEs to technological innovation has been a real development, the needs of SMEs to raise awareness, rely on themselves, to speed up the reform of property rights system; for entrepreneurs and technical personnel necessary incentives to continuously improve their quality; the establishment of technical alliances with other companies or universities and research institutions to form a development system; market-oriented, the development of specialized production and services; strengthening the subsequent management of technological innovation, improve its success rate to achieve the industrialization of technological innovation and commercialization.

\section{References}

[1] Wang-Ji C. Innovative Space: Enterprise Clusters and Regional Development. Peking University Press, 20012.

[2] Pan Kai. Enterprise Technology Innovation Management and Benefits, 1997 (3).

[3] Xiao-Jian Z, Su-Xiao Y. Firm Size Structure and SMEs Technological Innovation, Guangxi Social Sciences, 2002.2.

[4] Liu-Shu F. After WTO SME Technology Innovation Strategies, Technology Progress and Policy, 2002.6.

[5] Chen-Tian X. The Role of Government Policy on SMEs Technological Innovation, Nanjing University Of Economics, 2002.1. 